\title{
Flexural, Impact and Tensile behaviour of Environmental Friendly PLA Composite Plate
}

\author{
M. Selwin, N. Rajini
}

\begin{abstract}
The biodegradable nature and load bearing capacity of Polylactic Acid (PLA) made it as an exact replacement to conventional plastics in automobile applications. The natural fiber reinforced composites always showcase good mechanical features higher than the single fiber fortified composites and nearly have square with highlight as of engineered fiber composites. This paper displays the extraction and arrangement procedure of the Polylactic corrosive (PLA) composites utilizing the normally accessible fiber like Sansevieria fiber. Inferable from its high solidarity to weight proportion and vitality change these normal strands are equipped for supplanting engineered materials in different applications. Sansevieria fiber have the greatest elastic and effect quality when contrasted and other fiber composites. The outcome demonstrates that the Sansevieria composites have the greatest malleable and sway properties of normal composites with Polylactic corrosive.
\end{abstract}

Keywords: Bio-degradable, Sansevieria Roxburghiana, PLA

\section{INTRODUCTION}

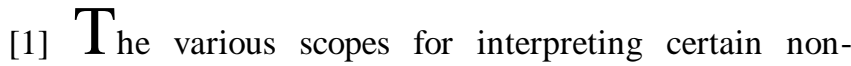
conventional sources for natural fibers is being explored. "Sansevieria Trifasciata fiber which has a great impact in textile industries is a lignocellulosic fiber. Water retting is one of the notable technique that is used for the extraction of Sansevieria Trifasciata from its leaves. In this study the extracted fiber was examined for its diameter, fineness, tensile strength and elongation in the laboratory. There is a possibility for favorably enhancing these properties through various techniques of mixing and green application processes. Rita Kant

[2] PLA and its copolymers are generally utilized for a wide assortment of utilizations. While they are viewed as biocompatible, symptoms coming about because of their implantation have been accounted for. The implantation of biomaterials dependably results in an outside body response. Such a response has additionally been accounted for following PLA and its copolymers.

This article surveys the procedure of provocative response that will be normal after implantation of PLA, and it features explicit cases in which the incendiary response can result in wellbeing concerns. The creators likewise survey chosen cases from various therapeutic fields to show conceivable clinical symptoms coming about because of its utilization.

\section{Yuval Ramot}

[3] PLA is delivered on huge scale and utilized for different applications, for example bundling for prescription, horticulture and material. Sadly, the weakness of PLA is significant disadvantage to limit its applications. So as to conquer these impediments, improvement the durability of
PLA by copolymerization, plasticization, mixing or by the generation of filled composites has been of intrigue. Mixing PLA with different polymers gives the most down to earth to toughening PLA. Elastomer has ordinarily been considered on the grounds that elastomer molecule carry on as pressure safeguard upgrading crack vitality ingestion of weak polymer. Moran Haim-Zaida

[4] Biodegradablepolymers are viewed as a potential answer for the natural issues produced by plastic waste. Specifically, the inexhaustible aliphatic polyesters of poly (hydroxyacid) type homo polymers and copolymers comprising of poly lactic corrosive (PLA) PLA has pulled specifically consideration as a substitute for ordinary oil based plastics. PLA is incorporated by the aging of inexhaustible agrarian sources, including corn, cellulose, and different polysaccharides. We talk about the debasement instruments of PLA and its altered structure in the earth, current issues that ruin the accomplishment of good PLA mix, and approaches to beat a portion of these issues. Moreover, our exchange is stretched out to cover the subjects of hydrolytic corruption and enduring impacts with various PLA mixes. [5] Biodegradable polymers, for example, poly (lactic) corrosive (PLA) have been contemplated for biomaterials applications, for example, characteristic human tendon substitution, anyway these materials could be connected to different parts as aviation, flight, car, sustenance bundling. For some current applications, PLA segments show collected perpetual misshaping coming about because of dynamic mechanical sources of info, coming about on disappointment by laxity of parts. Pointing the improvement of PLA mechanical properties, the joining of carbon nano fillers into PLA framework, explicitly. PLA and nano composites were created by soften mixing pursued by pressure forming in a hot press, with little weight rates of nano fillers. V.C.Pinto [6] Poly (lactic corrosive) (PLA), is the most investigated bio friendly polymer which is enquires universally up to now. Because of its benefits. The primary reason for this kind of investigation is to interpret the mechanical and physical features that influence its safety, processing capability, debasement. Further we discuss more about the upgradement of PLA such as Segments and adding plasticizers, nucleation specialist expansion, and PLA alterations and nano plans. Shady Farah

[7] The effects of adding and the improvements of tiny levels of Titanium Oxide nano components on the dynamic mechanical behavior of Poly Lactic Acid and PHBV, Poly Lactic Acid and PCL, PHBV/PCL additives are consolidated in this work.. The results suggests that the features of the PLA/PHBV mixtures was more formidable than the other mixtures in the temperature locale underneath the glass progress of PHBV. But the PLA/PCL and PHBV/PCL

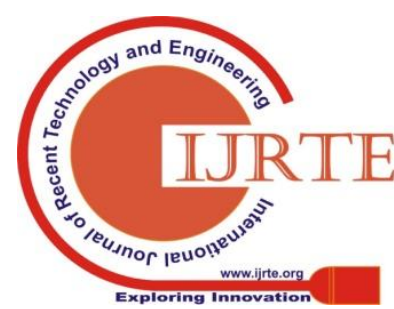


did not enumerate a comparative component. J.P. Mofokeng.

[8] When comparing to other printing techniques such as Screen printing and inkjet technology $3 \mathrm{D}$ printing possess a remarkable impacts on engineering texture and material functionalization.

The main objectives is to customize the usage of water, various bio components and to avoid various losses to improve the natural impacting and profit. The concern is to build up a coordinated or custom fitted generation process for keen and useful materials which keep away from superfluous utilization of water, vitality, synthetic compounds and limit the loss to improve natural impression and profitability. The layer by layer preparation of polymers and nano composites by Fused Deposition Modelling using vaporization is discussed. Different features which may enhance the bonding capability such as 3D printing parameters, layer by layer formation methods and additives type joined in the materials are discussed. Razieh Hushemi Sanatgar.

[9] This work suggests the various parameters of sansevieria natural fiber as fortification in the readiness of incompletely bio friendly green composites. The impact of fiber content on mechanical behavior of composite was investigated and found that rigidity and effect quality at greatest fiber content were 2.55 and 4.2 occasions to that of unadulterated tar, individually. Transverse warm conductivity of unidirectional composites was examined tentatively by a monitored warmth stream meter strategy. K. Ramanaiah

[1] [10] The result suggest that, to the extent AM PLA is concerned, the mean pressure impact in weakness can be demonstrated by essentially utilizing the greatest worry process As per the formulated re-testing talked in this work, when suitable trial outputs can't be created, the weakness evaluation can be performed by utilizing a reference weariness bend with negative backwards incline equivalent to 5.5 and continuance limit. AM PLA is portrayed by a weakness act like the one of PLA produced utilizing customary and entrenched advancements. O.H.Ezeh, L.Susmel

\section{MATERIALS}

\section{A. Natural Fibers}

\section{Sansevieria Roxburghiana}

The warm conductivity of the fiber diminishes with the expansion of fiber content. The expansion of Sansevieria decreases the Heat Release Rate. At the point when consumed it discharges more carbon dioxide than pitch composite. The rigidity of Sansevieria fiber is 2.55 occasions more prominent than gum and the effect quality is 4.2 occasions more prominent than the pitch. Elasticity of composite is expanded by $18.16 \%, 36.49 \%, 102.97 \%$, and $155.24 \%$ over virgin polyester at $0.12,0.21,0.28$, 0.36 volume division of filaments individually [6].

Revised Manuscript Received on December 20, 2019.

Mr. M. Selwin, Assistant Professor, Department of Mechanical Engineering, Kalasalingam Academy of Research and Education.

Dr. N. Rajini, Professor, Kalasalingam Academy of Research and Education.

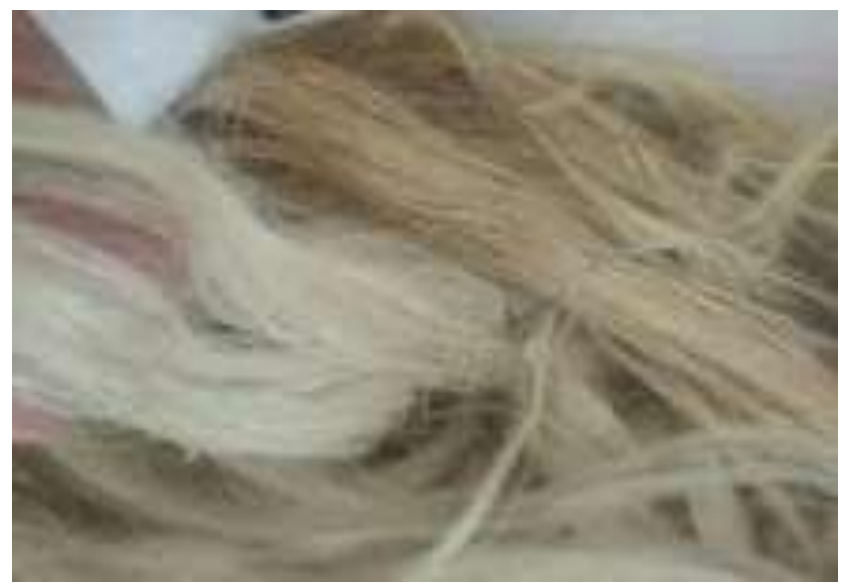

Fig.1. Extracted Sansevieria

\section{B. Polylactic corrosive}

Poly (lactic corrosive) or Polylactic corrosive or polylactide (PLA) is an environmental friendly biocompatible product prepared from corn starch, custard roots, chips or starch, or sugarcane. PLA had the second highest utilization volume of any natural plastic universally in 2010. [16]

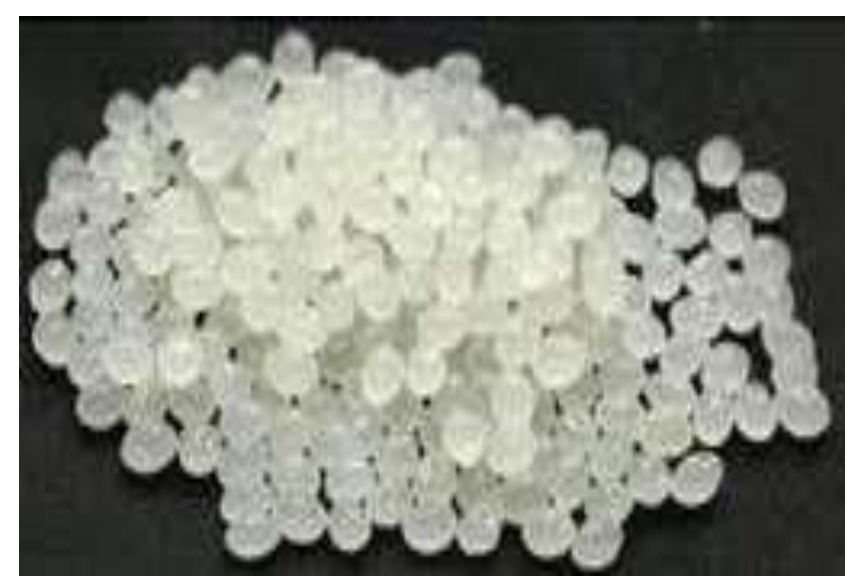

Fig.2. PLA Pellets

\section{PROBLEM IDENTIFICATION}

The pre-existing material which is used in the $3 \mathrm{D}$ printing technique is mostly composed of a Poly Hydroxy Butyrate co Valerate (PHBV) which is a standout amongst the most broad biomass-based, biodegradable (compostable) and biocompatible polymers. It is water-insoluble, can be either straightforward or semi-straightforward relying upon polymer crystallinity, and optically dynamic. The fundamental disadvantages of PHBV are high weakness, moderate crystallization rate, and high porousness to gases. The ways for beating these issues are to utilize plasticizers, copolymerization with different segments, making composites, and mixing with different polymers. So in order to find out an alternative to the pre-existing $3 \mathrm{D}$ printing material, a new composite has to be prepared which overcome its defects. Therefore a composite consisting of both Sansevieria Roxburghiana and Polylactic acid (PLA) is to be prepared. PLA likewise have the properties of fragility and low effect opposition and the rigidity of composite expanded with the adjustment in the volume portion of strands. Notwithstanding that so as to diminish the expense of the 
printing material and furthermore to lessen the danger in the previous material, this composite of PLA and Sansevieria Roxburghiana will be progressively needful.

\section{METHODOLOGY}

The fabrication and mechanical testing PLA and Sansevieria based composite specimen is done by the methodology given below.

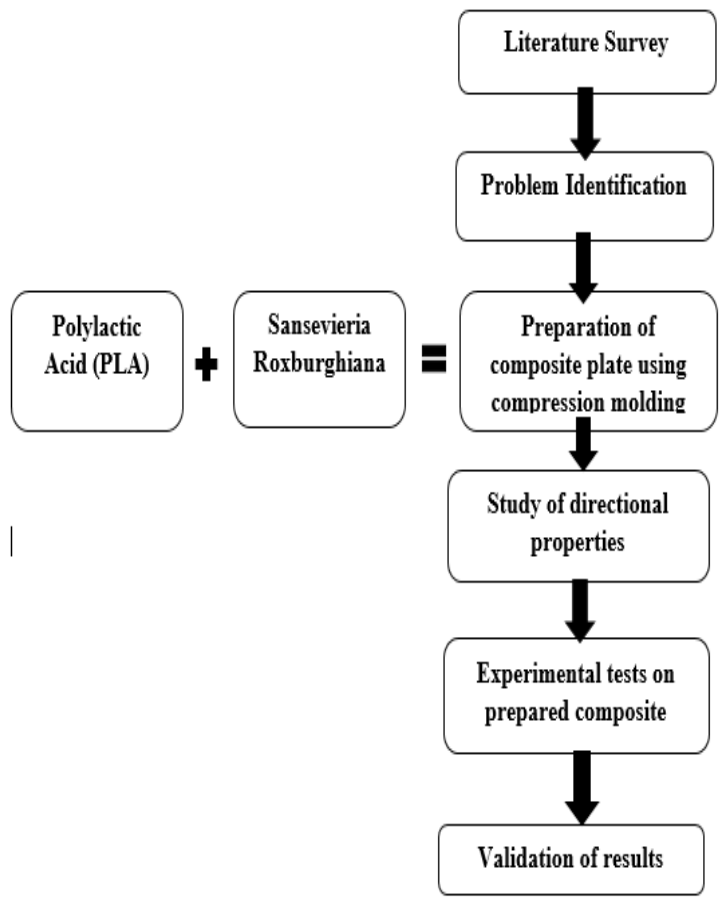

Fig.3. Methodology

\section{PROCESS OF FABRICATION}

\section{A. Injection Molding}

Infusion forming machine molds can be affixed in either an even or vertical position. Most of machines are evenly situated, yet vertical machines are utilized in some specialty applications, for example, embed forming, enabling the machine to exploit gravity. Some vertical machines likewise don't require the shape to be affixed. There are numerous approaches to attach the instruments to the platens, the most widely recognized being manual cinches (the two parts are dashed to the platens); be that as it may, water driven braces (chocks are utilized to hold the apparatus set up) and attractive clasps are additionally utilized. The attractive and water driven cinches are utilized where quick apparatus changes are required.

\section{B. Specimen Preparation}

Initially Sansevieria Roxburghiana fiber is prepared to be cut on different lengths such as $20 \mathrm{~mm}$. Pure fiber is separated which does not contain any green shades left over. Moreover, fine hair like structured fibers are separated in order to ensure that there are no thick pieces of fiber. This is done because such fibers can leads to improper plate preparation. The separated hair like fine fibers are eventually cut into different lengths. By injection molding the specimen is prepared for the following combinations.
Table.1. Specimen details

\begin{tabular}{|c|c|c|c|}
\hline $\begin{array}{c}\text { SPECIM } \\
\text { EN }\end{array}$ & PLA (\%) & FIBER (\%) & LENGTH \\
\hline 1 & $\mathbf{1 0 0}$ & 0 & $20 \mathrm{~mm}$ \\
\hline $\mathbf{2}$ & $\mathbf{8 0}$ & 20 & $20 \mathrm{~mm}$ \\
\hline
\end{tabular}

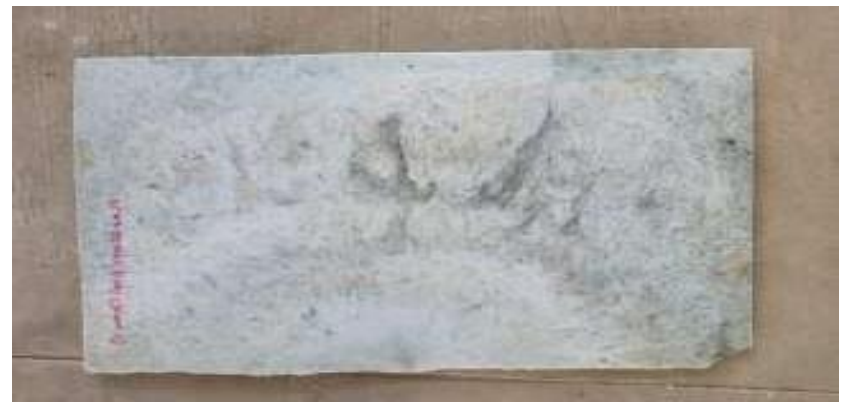

Fig.4. Composite Plate

\section{Testing of Composites}

Table 2. Testing Standards

\begin{tabular}{|c|c|c|}
\hline STANDARD & SPECIFICATION & TEST \\
\hline ASTM D638 & $165 \mathrm{~m} * 13 \mathrm{~mm} * 3 \mathrm{~mm}$ & Tensile \\
\hline ASTM & $127 \mathrm{~mm} * 13 \mathrm{~mm} * 3 \mathrm{~mm}$ & $\begin{array}{l}\text { Flexura } \\
1\end{array}$ \\
\hline D790-92 & & Impact \\
\hline ASTM D256 & $60 \mathrm{~mm}^{*} 13 \mathrm{~mm} * 3 \mathrm{~mm}$ & \\
\hline
\end{tabular}

\section{TEST RESULTS}

The test results are plotted on graph having $\mathrm{X}$-axis as sample number and the $\mathrm{Y}$-axis parameter is taken as strength obtained in each test results in $\mathrm{N} / \mathrm{mm} 2$. Three specimen for each testing gives twelve results in total. The average of the results is calculated and it is considered for the final conclusion. Thus the results are obtained and are plotted in the form of a graph which helps in providing a clear knowledge on the outcome of the results. The following table 3 consists of the list of results obtained from the appropriate test samples with pure PLA and PLA with fiber.

Table.3. Test Results

\begin{tabular}{|c|c|c|c|}
\hline S.no & Test parameters & Pure PLA & $\begin{array}{c}\text { PLA } \\
\text { with } \\
\text { Fiber }\end{array}$ \\
\hline 1 & Tensile Strength, N/mm ${ }^{2}$ & 41.56 & 19.38 \\
\hline 2 & Flexural Strength, N/mm ${ }^{2}$ & 118.24 & 89.38 \\
\hline 3 & Impact, Joules & 5.2 & 4.9 \\
\hline
\end{tabular}




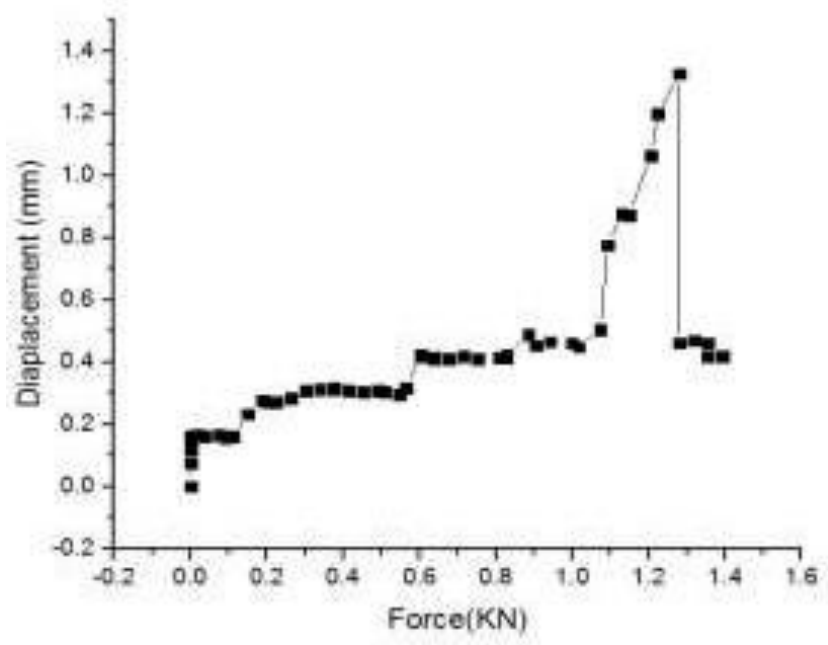

Fig.5. Tensile behaviour of Pure PLA

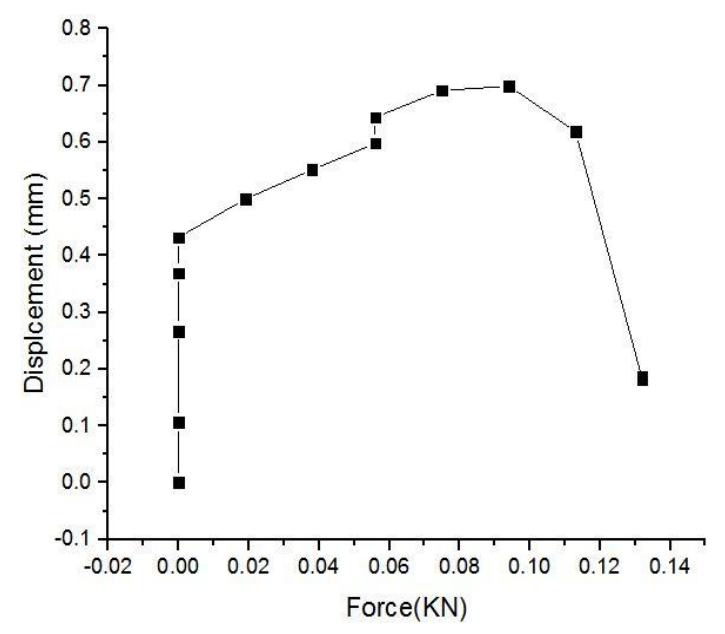

Fig.6. Load vs Displacement for PLA and Fiber

\section{CONCLUSION}

This study focuses on utilizing Sanseveria Roxburghiana fiber and poly lactic acid (PLA) powder as reinforcement towards producing bio degradable composites, thus bringing economic values to the Sanseveria Roxburghiana fiber. The Specimen of PLA and PLA fiber mixture is fabricated and the results shows that the sample with pure PLA $20 \mathrm{~mm}$ fiber has the highest tensile strength when compared to PLA with fiber samples. Similarly, pure PLA contain high flexural strength and eventually PLA with fiber sample contain high impact strength.

\section{REFERENCE}

1. Elsawy, M. A., Kim, K. H., Park, J. W., \& Deep, A. (2017). Hydrolytic degradation of polylactic acid (PLA) and its composites. Renewable and Sustainable Energy Reviews, 79, 1346-1352.

2. Ezeh, O. H., \& Susmel, L. (2018, July). On the fatigue strength of 3D-printed polylactide (PLA). In Prcedia Structural Integrity (Vol. 9, pp. 29-36). Elsevier.

3. Farah, S., Anderson, D. G., \& Langer, R. (2016). Physical and mechanical properties of PLA, and their functions in widespread applications - A comprehensive review. Advanced drug delivery reviews, 107, 367-392.

4. Kant, R., \& Alagh, P. Extraction of Fiber from Sansevieria Trifasciata Plant and its Properties
5. Mofokeng, J. P., \& Luyt, A. S. (2015). Dynamic mechanical properties of PLA/PHBV, PLA/PCL, PHBV/PCL blends and their nanocomposites with $\mathrm{TiO} 2$ as nanofiller. $\mathrm{Zx} /$ Thermochimica acta, 613, 41-53.

6. Pinto, V. C., Ramos, T., Alves, S., Xavier, J., Tavares, P., Moreira, P. M G. P., \& Guedes, R. M. (2015). Comparative failure analysis of PLA PLA/GNP and PLA/CNT-COOH biodegradable nanocomposites thin films. Procedia Engineering, 114, 635-642.

7. Ramot, Y., Nyska, A., Markovitz, E., Dekel, A., Klaiman, G., Zada, M H., \& Maronpot, R. R. (2015). Long-term local and systemic safety of poly (1-lactide-co-epsilon-caprolactone) after subcutaneous and intra-articular implantation in rats. Toxicologic pathology, 43(8), 1127-1140.

8. Ramanaiah, K., Prasad, A. R., \& Reddy, K. H. C. (2013). Mechanical, thermo physical and fire properties of sansevieria fiber-reinforced polyester composites. Materials \& Design, 49, 986-991.

9. Sanatgar, R. H., Campagne, C., \& Nierstrasz, V. (2017). Investigation of the adhesion properties of direct 3D printing of polymers and nanocomposites on textiles: Effect of FDM printing process parameters. Applied Surface Science, 403, 551-563.

10. Taiwat Talbamrug, Chayannee Kasemook, Worawit Sangetan (2016). Mechanical, thermal, and biodegradability properties of PLA/modified starch blends. Polymer composites, 32(12), 2093-2100.

\section{AUTHORS PROFILE}

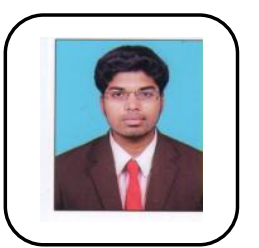

Mr. M. Selwin, have completed his M.E in Manufacturing Engineering. His area of research is Natural Composites. He is currently working as an Assistant Professor in the Department of Mechanical Engineering in Kalasalingam Academy of Research and Education.

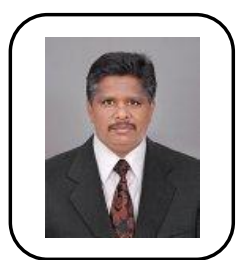

Dr. N. Rajini is a Professor in Kalasalingam Academy of Research and Education. His area of Research is Bio Composites. His Citation is 1320 , h index is 19 and i10 index is 32 . He is doing his project in Bio composites. He have several research collaborations with foreign countries. 